\section{Da cromatina sexual de Decourt ao PCR em tempo real: citogenética e expressão gênica no estudo da síndrome de Turner}

\author{
From Decourt sex chromatin to real time PCR: cytogenetic \\ and gene expression in the Turner syndrome study
}

Bianca Bianco', Monica V. N. Lipay', Alexis D. Guedes', Kelly C. Oliveira' ${ }^{\prime}$ leda T. N. Verreschi'

$\mathrm{E}$ m 1930, o pediatra alemão Otto Ullrich relatou o caso de uma menina de 8 anos de idade que apresentava palato em ogiva, ptose palpebral, orelhas de implantação baixa, linfedema, baixa estatura, ausência de desenvolvimento de mamas, ausência ou quantidade mínima de pelos pubianos e axilares, cúbito valgo e pescoço alado. No entanto, a primeira visão equivalente à síndrome foi feita por Morgagni em 1761 (1).

Em 1938, Henry Turner (2) publicou a descrição de pacientes do sexo feminino que se caracterizavam por apresentar os mesmos sinais descritos por Otto Ullrich (1930). Quatro anos depois, Varney e cols. (3) e Albright e Smith (4), independentemente, demonstraram em pacientes com sinais clínicos semelhantes aos daqueles descritos por Turner que, após a idade puberal, apresentavam um elevado nível de gonadotrofinas urinárias, estabelecendo que se tratava de uma anormalidade da função gonadal e não uma deficiência hipotalâmica ou hipofisária. Em 1944, Wilkins e Fleischmann (5) observaram, em análises histológicas, que as pacientes com os sinais descritos por Turner (2), Varney e cols. (3) e Albright e Smith (4) deveriam ter gônadas em fita e que todos esses autores estavam estudando a mesma síndrome: a síndrome de Turner (ST).

A primeira investigação cromossômica dessa síndrome foi realizada na Escola Paulista de Medicina, hoje Universidade Federal de São Paulo - Unifesp, em 1954 por Décourt e cols. (6) que demonstraram que os sinais fenotípicos característicos da ST eram decorrentes da ausência da cromatina sexual. Em 1959, Ford e cols. (7) descreveram a anormalidade cromossômica que caracterizava a síndrome de Turner: monossomia do cromossomo sexual X, o cariótipo 45,X.

Dados de literatura referem que um segundo cromossomo sexual é necessário à sobrevivência do feto e, desse modo, virtualmente todo nascido vivo 45, X apresentaria mais de uma linhagem celular compondo seu cariótipo, constituindo assim um mosaico. Essa condição seria necessária a pelo menos alguns órgãos, durante determinado período da embriogênese. Essa hipótese se baseia em dois pontos principais: a frequência de mosaicismo do cromossomo sexual é muito superior em nascidos vivos com ST em relação à observada em abortos; estima-se que aproximadamente $99 \%$ dos embriões puramente $45, \mathrm{X}$ morrem no útero. Todavia, a seleção natural nem sempre prevalece quando o mosaicismo está presente, apesar de o resultado fenotípico ser semelhante (8).

A detecção de mosaicismo é determinada, principalmente, por quatro fatores: o tipo e o número de tecidos analisados, o número de células estudadas, a sensibi-
' Disciplina de Endocrinologia, Departamento de Medicina, Universidade Federal de São Paulo (Unifesp), São Paulo, SP, Brasil

Correspondência para: leda T. N. Verreschi

Rua Pedro de Toledo, 781 $13^{\circ}$ andar

04039-032 - São Paulo, SP, Brasil ieda.verreschi@unifesp.br

Recebido em 8/Mar/2010 Aceito em 17/Mar/2010 
lidade das técnicas aplicadas e a possibilidade de seleção, que pode resultar na eliminação de linhagens celulares ao longo do desenvolvimento. A presença de mosaicismo em baixa frequência pode não ser detectada pela técnica de citogenética clássica, pois esse tipo de análise requer um número grande de células. A aplicação de técnicas moleculares, como a hibridação in situ fluorescente (FISH) e a reação em cadeia da polimerase (PCR), melhora substancialmente a detecção de linhagens celulares em baixa frequência e de possíveis alterações estruturais (9).

Nazarenko e cols. (10) verificaram que a análise citogenética pode não fornecer informações precisas sobre a presença de mosaicismo cromossômico em pacientes com ST. A análise adicional de células de tecidos de diferentes origens embrionárias (linfócitos da mesoderme associada à análise de células do epitélio bucal da endoderme), por exemplo, permite uma definição mais precisa do diagnóstico citogenético. A análise por FISH com sonda para o cromossomo X permitiu um resultado mais acurado, evidenciando que $29 \%$ das 50 pacientes analisadas com monossomia pura detectada por cariótipo apresentavam, na verdade, mosaicos. Ainda segundo esses autores, foi observado que havia uma constituição cromossômica distinta em diferentes tecidos do mesmo indivíduo, salientando a possibilidade de que alterações cromossômicas ou a presença de um segundo cromossomo sexual podem estar ausentes no sangue, mas presentes em outros tecidos.

A investigação por PCR é mais efetiva do que a análise citogenética para a detecção de mosaicismo oculto envolvendo o cromossomo $\mathrm{Y}$ e pode ser também mais efetiva por meio de uma abordagem de múltiplos tecidos, aumentando as chances de verificação de mosaicismo, caso esteja presente (11). A abordagem que envolve investigação do mosaicismo para sequências Y-específicas por técnicas moleculares aumentou muito nos últimos anos, sendo adotada pela maioria dos serviços que trabalham no acompanhamento ou no diagnóstico dessa síndrome.

Tradicionalmente, é recomendada que a pesquisa de fragmentos do cromossomo Y na ST deva ser realizada em apenas duas situações: quando há sinais de virilização e/ou quando há a presença de cromossomo marcador não identificado pela citogenética clássica (9). No entanto, Canto e cols. (12) estudaram por PCR 107 portadoras da ST com cariótipo 45,X. Foi identificado material do cromossomo Y em $10(9,3 \%)$ das pacientes. A gonadectomia profilática foi indicada e, das seis pacientes que concordaram em realizar a cirurgia, duas apresentaram gonadoblastoma, revelando uma incidência de $33 \%$.

Bianco e cols. (11) estudaram 20 pacientes com ST por PCR em amostras de diferentes tecidos e encontraram que sete $(35 \%)$ das pacientes $45, \mathrm{X}$ apresentavam sequências cromossomo Y-específicas em pelo menos um tecido estudado. Dessas pacientes, quatro (14\%) foram submetidas à gonadectomia profilática e um gonadoblastoma bilateral foi encontrado numa paciente de 16 anos. A presença de sequências do cromossomo Y nessa paciente não estava associada à virilização, sinalizando que a ausência dessa característica não exclui a possibilidade de detecção de fragmentos ocultos do cromossomo Y.

Existem ainda controvérsias quanto aos genes do cromossomo Y que devem ser investigados, uma vez que o suposto locus para o gene do gonadoblastoma é cada vez mais considerado um mito. A maioria das investigações elegeu o gene $S R \Upsilon$ como o mais provável candidato à indução da cascata de eventos desencadeantes do processo de malignização das gônadas disgenéticas.

Bianco e cols. (13) verificaram que o gene $S R Y$ e não o TSPY estava relacionado ao desenvolvimento de lesões em gônadas disgenéticas desses pacientes. Em outro estudo, o mesmo grupo (14) investigou a presença de mosaicismo oculto do cromossomo Y (SRY e TSPY por PCR em pacientes com ST para estabelecer conduta preventiva ao desenvolvimento de tumores gonadais por gonadectomia profilática nas portadoras com presença dessas sequências. Em conclusão, tais investigações possibilitaram um panorama mais informativo desse tipo tumoral, por estudo da expressão de genes relacionados à determinação e à diferenciação sexual e ao desenvolvimento de tumores gonadais (SRY, WTI, SF1, STRA8, TSPY, OCT4, GATA4, FOG2 e DAXI) por qRT-PCR nas gônadas das pacientes submetidas à gonadectomia profilática. Das 104 pacientes estudadas, foi detectado mosaicismo oculto do cromossomo $\mathrm{Y}$ em 17 delas (16,3\%) com presença do SRY em todas, sendo que quatro delas $(3,8 \%)$ apresentaram também o gene TSPY. Dessas pacientes, 12 concordaram em realizar a gonadectomia profilática. Em dois casos, foi encontrado gonadoblastoma bilateral; em outros dois casos, hiperplasia das células do hilo e, em um deles também luteoma estromal. Não foram constatadas alterações significativas entre as gônadas disgenéticas e as controles na expressão dos genes estudados, exceto para os genes SRY, TSPY e OCT4 em ambas as gôna- 
das de uma paciente com constituição cromossômica $45, \mathrm{X} / 45, \mathrm{X}, \operatorname{add}(15)(\mathrm{pll})$.

Esses fatos demonstram que a investigação sistemática de sequências cromossomo Y-específicas é clinicamente importante na ST. A análise da expressão de genes que podem estar alterados no microambiente das gônadas disgenéticas dessas pacientes, como os genes SRY, TSPY e OCT4, demonstra que, nesse contexto, a exposição em longo prazo desses fatores pode contribuir para a transformação maligna mesmo na ausência de alterações histopatológicas. A detecção precoce desses eventos pode ser de grande valia na prevenção do desenvolvimento de tumores gonadais (14).

O tempo aperfeiçoou as ferramentas de investigação, tornando-as mais rápidas, precisas e sensíveis. $\mathrm{O}$ acesso à informação transformou os bancos de dados disponíveis na internet em fontes inesgotáveis de informação atual e completa. Felizmente no Brasil dispomos de excelentes grupos capazes de traduzir essa missão, desde os primórdios da investigação citogenética e celular até os dias de hoje.

Como demonstrado no estudo de Barros e cols. (15), consideramos que, além do aprimoramento da avaliação citogenética, fatores como o aumento do número de células investigadas, a análise por bandamento cromossômico, permitindo uma melhor caracterização das alterações estruturais tão frequentes nessa síndrome, a introdução das técnicas de avaliação molecular, determinando os riscos de modo precoce e seguro, e a estruturação de equipes multidisciplinares, que permitiram que o diagnóstico da ST seja cada vez mais precoce para um número crescente de meninas portadoras, seguido de um acompanhamento em longo prazo, resultam seguramente na redução das morbidades associadas e na melhoria da qualidade e expectativa de vida dessas pacientes. Este tem sido o objetivo do nosso grupo desde o estudo pioneiro do doutor Décourt sobre a síndrome de Turner.

Declaração: os autores declaram não haver conflitos de interesse científico neste estudo.

\section{REFERÊNCIAS}

1. Beiguelman B. Citogenética humana. Rio de Janeiro: Guanabara Koogan; 1982.

2. Turner HH. A syndrome of infantilism, congenital webbed neck, and cubitus valgus. Endocrinology. 1938;23:566-74.

3. Varney RF, Kenyon AT, Koch FC. An association of short stature, retarded sexual development and high urinary gonadotropin titers in women. Ovarian dwarfism. J Clin Endocrinol. 1942;2 (3):137-45.

4. Albright $\mathrm{F}$, Smith PH. A syndrome characterized by primary ovarian insufficiency and decreased stature. Report of eleven cases, with a digression on hormonal control of axillary and pubic hair. Am J Med Sci. 1942;204:625-48.

5. Wilkins L, Fleischmann W. Ovarian agenesis: pathology, associated clinical symptoms and the bearing on the theories of sex differentiation. J Clin Endocrinol. 1944;4:357-75.

6. Décourt L, SassoWS, Chiorboli E, Lima MC, Fernandes JM. Sobre o sexo genético na síndrome de Turner. Rev Assoc Med Brasil. 1954;1(2):203-6.

7. Ford CE, Jones KW, Polani PE, De Ameida JC, Briggs JH. A sexchromosome anomaly in a case of gonadal dysgenesis (Turner's syndrome). Lancet. 1959;1(7075):711-3.

8. Hassold T, Beham F, Leppert M. Cytogenetic and molecular analysis of sex-chromosome monosomy. Am J Hum Genet. 1988;42(4):534-41.

9. Oliveira RMR, Verreschi ITN, Lipay MVN, Eça LP, Guedes AD, Bianco B.Y chromosome in Turner syndrome: review of the literature. Sao Paulo Med J. 2009;127(6):373-8.

10. Nazarenko SA, Timoshevsky VA, Sukhanova NN. High frequency of tissue-specific mosaicism in Turner syndrome patients. Clin Genet. 1999;56:59-65.

11. Bianco B, Lipay MVN, Melaragno MI, Guedes AD, Verreschi ITN. Detection of hidden $Y$ mosaicism in Turner's syndrome: importance in the prevention of gonadoblastoma. J Pediatr Endocrinol Metab. 2006;19:1113-8.

12. Canto P, Kofman-Alfaro S, Jimenez AL, Soderlund D, Barron C, Reyes $\mathrm{E}$, et al. Gonadoblastoma in Turner syndrome patients with nonmosaic 45,X karyotype and $\mathrm{Y}$ chromosome sequences. Cancer Genet Cytogenet. 2004;1:70-2.

13. Bianco B, Lipay M, Guedes A, Oliveira K, Verreschi IT. SRY gene increases the risk of developing gonadoblastoma and/or nontumoral gonadal lesions in Turner syndrome. Int J Gynecol Pathol. 2009;28(2):197-202.

14. Bianco B, Oliveira KC, Guedes AD, Barbosa CP, Lipay MVN, Verreschi ITN. OCT4 gonadal gene expression related to the presence of Y-chromosome sequences in Turner syndrome. Fertil Steril. 2010. [Epub ahead of print].

15. Barros BA, Maciel-Guerra AT, De Mello MP, Coeli FB, de Carvalho $A B$, Viguetti-Campos $N$, et al. The inclusion of new techniques of chromosome analysis has improved the cytogenetic profile ofTurner syndrome. Arq Bras Endocrinol Metabol. 2009;53(9):1137-42. 